\title{
AS TECNOLOGIAS DIGITAIS DA INFORMAÇÃO E COMUNICAÇÃO COMO MEDIADORAS NA ALFABETIZAÇÃO DE PESSOAS COM TRANSTORNO DO ESPECTRO DO AUTISMO: UMA REVISÃO SISTEMÁTICA DA LITERATURA \\ DIGITAL INFORMATION AND COMMUNICATION TECHNOLOGIES AS MEDIATORS IN THE LITERACY OF PEOPLE WITH THE AUTISM SPECTRUM DISORDER: A SYSTEMATIC LITERATURE REVIEW
}

\author{
Josiane Almeida da Silva \\ Universidade Católica de Pernambuco, Brasil \\ josy.almeida33@yahoo.com.br \\ Michele Elias de Carvalho \\ Universidade Católica de Pernambuco, Brasil \\ michelejoaos@yahoo.com.br \\ Roberta Varginha Ramos Caiado \\ Universidade Católica de Pernambuco, Brasil \\ caiado.roberta@gmail.com \\ Isabela Barbosa Rêgo Barros \\ Universidade Católica de Pernambuco, Brasil \\ isabela.barros@unicap.br
}

\begin{abstract}
RESUMO: Esta pesquisa objetiva discutir o uso das Tecnologias Digitais da Informação e Comunicação no processo de alfabetização e aprendizagem de pessoas com Transtorno do Espectro do Autismo. Como procedimento metodológico, utilizou-se a revisão sistemática da literatura. Nessa perspectiva, foi realizado um levantamento dos artigos científicos nacionais publicados entre 2014 e 2019 disponibilizados no Portal de periódicos Capes e Scielo. Para tanto, foi efetuada uma busca avançada combinando os descritores Transtorno do Espectro do Autismo, Autismo, Tecnologia, Alfabetização, Educação, Aprendizagem e Software. Os textos foram selecionados conforme os critérios de inclusão: pesquisas nacionais que investigassem o uso das referidas tecnologias para alfabetização e aprendizagem de pessoas com o transtorno, publicadas entre 2014 e 2019. Como critérios de exclusão: artigos voltados à esfera da saúde; estudos nos quais as Tecnologias Digitais da Informação e Comunicação foram utilizadas com sujeitos sem o transtorno e artigos repetidos em ambas as bases de dados. Como resultados, foram encontrados 198 trabalhos e, após análise e aplicação dos critérios de inclusão e exclusão, restaram sete pesquisas que contemplavam o tema. Os estudos analisados demonstraram as contribuições das tecnologias para a alfabetização e aprendizagem das pessoas com o transtorno em questão, porém ainda existe uma grande carência de pesquisas nessa área.
\end{abstract}

PALAVRAS-CHAVE: autismo; tecnologia; aprendizagem; alfabetização.

ABSTRACT: This research aims at discussing the use of Digital Information and Communication Technologies in the literacy and learning process of people with the 
Autism Spectrum Disorder. As a methodological procedure, a survey of the national scientific articles published between 2014 and 2019 was made available in the Portal of Capes and Scielo journals. To do so, an advanced search was performed, combining the descriptors Autism Spectrum Disorder, Autism, Technology, Literacy, Education, Learning and Software. The texts were selected according to inclusion criteria: national surveys that investigated the use of these technologies for literacy and learning of people with the disorder published between 2014 and 2019. As exclusion criteria: health-related articles; studies in which the Digital Information and Communication Technologies were used with people without the disorder and articles repeated in both databases. As a result, 198 papers were found and, after analysis and application of the inclusion and exclusion criteria, there were seven works that contemplated the theme. The studies analyzed demonstrated the contributions of technologies for literacy and learning of people with the disorder in question, but there is still more research needs to be done in this area.

KEYWORDS: autism; technology; learning; literacy.

\section{Introdução}

A alfabetização no Brasil tem passado por mudanças significativas ao longo dos tempos. A cada momento vivenciado pelos usuários e estudiosos da Língua Portuguesa (LP), diversificam-se os objetivos e intencionalidades traçados para seu ensino. Esses fatores evidenciam alterações nas necessidades comunicativas da sociedade, e, por consequência, nas estratégias de ensino e aprendizagem da leitura e da escrita.

O termo "alfabetização" certamente remete à memória do interlocutor o domínio de competências referentes à leitura e à escrita. No entanto, essa tarefa até hoje é considerada um desafio em algumas sociedades. Na história da alfabetização no Brasil, o persistente fracasso da escola no ensino da linguagem escrita às crianças configura-se como um dos principais fatores responsáveis pelas constantes mudanças de paradigma e concepção de métodos (SOARES, 2016).

Nesse sentido, durante muitas décadas, houve a oscilação entre um método e outro, dada a constatação da ineficiência deles para a aprendizagem da escrita. Hora um, hora outro método surgia como solução para os problemas da alfabetização.

Segundo Palangana (1998), a teoria construtivista surge no Brasil em meio a essa crise entre paradigmas metodológicos. Nesse momento, o conceito de alfabetização passa por uma profunda mudança teórico-metodológica, cuja trajetória de déficits e insucesso dos alunos, no que diz respeito ao domínio da lectoescrita (MORTATTI, 2004), consistia em uma preocupação para gestores em educação, professores e estudiosos da área. Essa inquietação ocorria devido aos altos índices de repetência na primeira série do ensino fundamental, e, em consequência disso, o contingente alarmante de evasão nessa mesma etapa da escolarização.

Essa teoria foi introduzida no campo da educação por meio dos estudos da psicolinguística moderna, representada por Ferreiro e Teberosky, (2007), por volta dos anos 1962. Esses estudos geraram um grande movimento de reestruturação do processo de ensino e aprendizagem. A partir daí, os estágios percorridos pelo aprendiz na construção do conhecimento acerca da escrita, assim como as hipóteses elaboradas por ele nesse processo, passam a ser levadas em consideração pelo professor, permitindo a 
interpretação das etapas vivenciadas durante a alfabetização, ao invés dos "erros" cometidos pelos alfabetizandos.

Desse momento em diante a aprendizagem passou a ser vista como um processo que não passa pela aquisição de elementos isolados, mas sim pela constituição de sistemas nos quais o valor das partes vai se redefinindo em função das mudanças no sistema total, demonstrando a existência de erros construtivos (FERREIRO; TEBEROSKY, 2007).

De acordo com Coutinho (2005), durante a apropriação do Sistema de Escrita Alfabética (SEA), a criança passa a formular hipóteses para responder o que e como a escrita representa os sons da fala, passando por etapas ou níveis de compreensão desse sistema.

Nessa perspectiva, no construtivismo defende-se a ideia de que sejam proporcionadas à criança oportunidades de aprendizagem por meio da interação com materiais reais de leitura e de escrita (SOARES, 2016). Ou seja, por meio de diferentes gêneros textuais que circulam socialmente, incentiva-se 0 descarte de textos artificialmente elaborados para "ensinar/aprender a ler", extrapolando, assim, o ensino focado no uso de um método específico e restrito em si mesmo.

Com o advento e difusão das novas tecnologias e, consequentemente, a circulação dos gêneros textuais nas esferas digitais, surge a necessidade de um novo olhar diante do processo de aquisição da escrita. Com isso, faz-se necessário que os professores repensem o significado da alfabetização para que se possa incluir a assimilação de outros registros, tais como imagens, sons, vídeos, diferentes do texto escrito, fato que passou a demandar outras habilidades ou, como denominado por Pischetola (2016), uma alfabetização digital.

As TDICs desempenham um papel importante no acesso à informação, nos modos de aprendizagem, e isso demanda da sociedade alguns desafios de como lidar com as diversas linguagens potencializadas pelas tecnologias digitais (CANI; COSCARELLI, 2016 p. 15). Assim, essas novas habilidades, exigidas pela era da cibercultura e da Web 3.0, pedem que o professor saiba atuar com os novos mecanismos de acesso à informação no ambiente digital.

Atualmente, as estratégias metodológicas utilizadas no processo de alfabetização vêm sendo enriquecidas com recursos tecnológicos como jogos digitais, plataformas, aplicativos para computadores, tablets, smartphones e iPads. Isso permite a inserção, no ambiente da sala de aula, de recursos que já fazem parte da realidade de muitos estudantes, visando minimizar as dificuldades que eles apresentam durante a aquisição da escrita. Esses recursos podem também beneficiar alunos e professores no processo de construção dos conhecimentos científico e acadêmico.

De acordo com a teoria sociocultural, presente nos estudos de Vigotski (2008), os seres humanos interagem com o meio ambiente e com os seus semelhantes por meio de instrumentos culturais e históricos. Isso implica dizer que os instrumentos e signos exercem o papel de mediadores das relações tipicamente humanas. Assim, a mediação é a intervenção de um elemento intermediário em uma relação que o homem tem com o objeto, com outros seres humanos e consigo mesmo (FIGUEIREDO, 2019).

Alguns autores, como Ferreira (2011), avaliaram o surgimento da oralidade de uma criança com Paralisia Cerebral (PC) por meio da mediação de um instrumento 
tecnológico. A Figura 1 demonstra ações ocorridas durante o processo de interação da criança avaliada e os jogos digitais. Dessa forma, foi possível perceber como se deu a intervenção com as TDICs para estimular a linguagem da pessoa com deficiência.

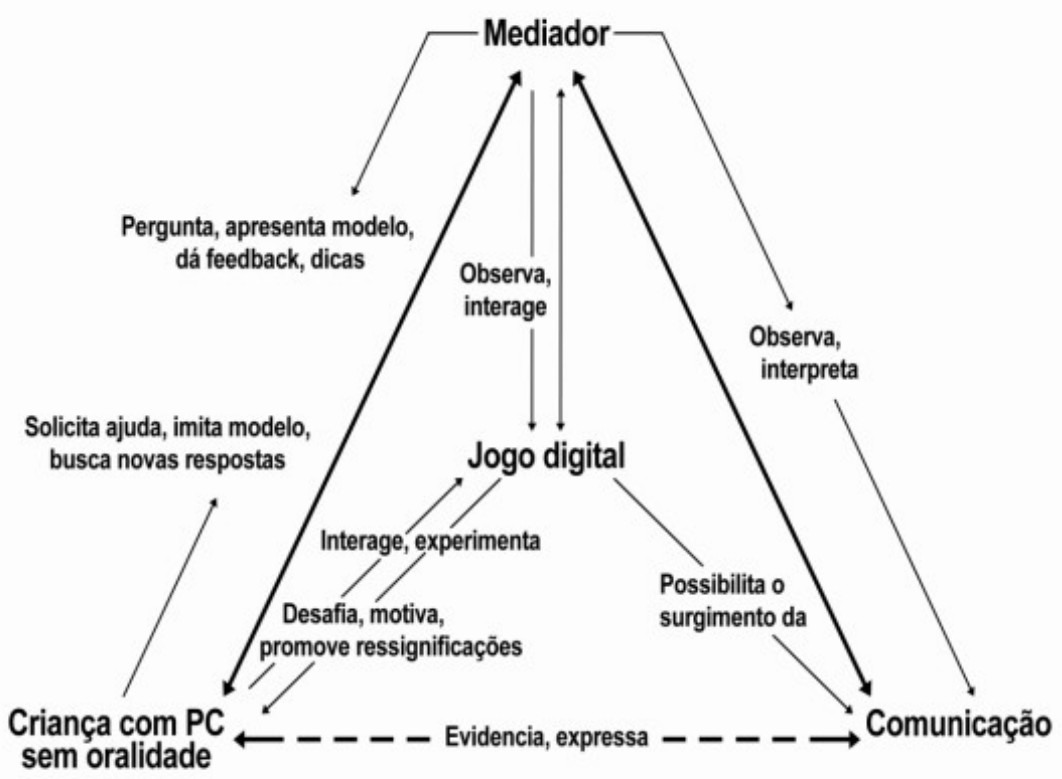

Representação do processo de mediação das crianças com PC sem oralidade, adaptado de Vygotsky (2009).

Figura 1: Registro dos processos ocorridos durante a mediação por meio de um jogo digital utilizado com uma criança com Paralisia Cerebral não oralizada.

Fonte: Ferreira (2011).

Se, no Brasil, ainda há grandes desafios no que diz respeito à alfabetização de crianças que não apresentam dificuldades de aprendizagem, o que se pode dizer a respeito daquelas que possuem algum transtorno ou deficiência?

Acredita-se que esse desafio se torna ainda maior quando esse processo é voltado para pessoas com transtorno do Espectro do Autismo (TEA), visto que esse é um transtorno considerado relativamente novo e todos os estudos nessa área ainda são recentes. Além disso, a pessoa com TEA possui uma série de singularidades que demandam maiores cuidados diante das estratégias a serem utilizadas no seu processo de aprendizagem.

O autismo começa a ser oficialmente mencionado na literatura científica por volta do final da década de 1930 e início de 1940, a partir do artigo "Distúrbios Autísticos do Contato Afetivo" (KANNER, 1943). Esse estudo descreveu as singularidades de um grupo de onze crianças, cujas idades compreendiam entre dois e onze anos, que apresentavam dificuldades de se relacionar com pessoas, déficit no uso da linguagem para comunicação social de forma funcional, resistência a mudanças, fixação excessiva por manter tudo igual, preferência por objetos em vez de pessoas.

Essas características, à época da realização do estudo, eram associadas a doenças mentais e aqueles que as apresentavam eram classificados como débeis 
mentais, esquizofrênicos ou psicóticos. A publicação do artigo foi um marco na história do autismo, pois seu autor desvinculou as características do transtorno das doenças mentais, atribuindo-Ihes o que ficou conhecido como Síndrome de Kanner e, atualmente, TEA (BRAGA, 2018).

Diversas hipóteses foram levantadas na tentativa de explicar sua origem; porém, até hoje, sua gênese ainda é desconhecida, embora as pesquisas nessa área estejam avançando. O que se tem de comprovação científica é que se trata de uma condição neurobiológica que inclui, de acordo com o Manual Diagnóstico e Estatístico de Transtornos Mentais - DSM 5 - transtornos de início precoce com déficits de comunicação social, comportamentos repetitivos e estereotipados (APA, 2013). Além disso, os estudos mais recentes começam a atribuir as causas do TEA a fatores de ordem genética e biológica, visto que o foco de algumas pesquisas é a identificação de alterações no processo de interações entre os genes e o ambiente (CASELLA; CELERI; MONTENEGRO, 2018, p. 11).

Já na esfera educacional, o processo de ensino e a aprendizagem da pessoa com TEA tem se configurado como um desafio para muitos pais, educadores e demais profissionais, tendo em vista que essas pessoas possuem condições subjetivas que necessitam de intervenções multidisciplinares e que a intensidade de suas características varia de indivíduo para indivíduo.

O desconhecimento acerca das peculiaridades apresentadas por esse sujeito, a falta de recursos pedagógicos adequados, que possam atender às suas necessidades específicas sem causar-lhe desconforto, são algumas barreiras que podem dificultar a aprendizagem da pessoa com TEA.

Instrumentos como os Sistemas de Comunicação Alternativa e Ampliada podem ser utilizados para minimizar dificuldades na interação de pessoas que possuem déficit na linguagem oral, pois elas têm como benefício o uso da linguagem visual, sonora e/ou verbal, que podem facilitar a interação entre o indivíduo e a aprendizagem (BERSCH; SCHIRMER, 2005, p. 89).

Dessa maneira, a aquisição da escrita pelos estudantes com esse transtorno ainda vem se desenhando em um cenário de pesquisa bastante carente, visto que eles ainda enfrentam grandes dificuldades durante seu processo de aprendizagem, mesmo tendo garantido por lei o direito à educação de qualidade nas escolas e ao "Atendimento Educacional Especializado - AEE" (BRASIL, 1988; 2008, 2012, 2015).

Diferentes metodologias de ensino têm sido defendidas e aplicadas para a aprendizagem de estudantes com deficiências e transtornos. Elas vão desde modelos baseados na teoria cognitivo comportamental (LEFRANÇOIS, 2017), como, por exemplo, o método ABA (LAURENT, 2014; LOVAAS, 1987) e Teacch (FONSECA; CIOLA, 2016), até os que se apresentam como fundamentados no sociointeracionismo (PALANGANA, 1998), dentre eles, o DIR Floortime, que está pautado na interação entre os indivíduos participantes. Esse método busca a compreensão das diferenças emocionais, sociais e intelectuais da criança no funcionamento motor, sensorial e de linguagem (HESS, 2013).

Muitos profissionais ainda não têm contato com esses novos modelos de ensino; no entanto, buscam desenvolver ou adaptar outros recursos metodológicos que possam auxiliar na aprendizagem de seus alunos. Isso nos leva a perceber que ainda há uma limitação no que diz respeito ao acesso a todos os meios educacionais existentes e que 
poderiam contribuir para o desenvolvimento da pessoa com TEA.

Nessa direção, as tecnologias digitais também podem ser grandes aliadas no processo de alfabetização e aprendizagem de pessoas com TEA, visto que é um meio que chama a atenção por possuir interfaces permeadas de linguagens visuais e sonoras. Portanto, nos últimos anos, a contribuição da tecnologia para o acesso ao conhecimento das pessoas com deficiência e/ou transtorno tem se tornado uma realidade.

Dessa forma, Mattar, (2010) afirma que já não é possível separar a tecnologia da educação, já não é impossível pensar as duas coisas desvinculadas. É crucial a ampliação do desenvolvimento de ferramentas tecnológicas, nesse contexto, a fim de viabilizar e estimular a aprendizagem das pessoas que apresentam TEA.

Levando em consideração os possíveis efeitos positivos da tecnologia para a alfabetização e aprendizagem das pessoas com TEA, o presente estudo traz como indagação: quais são as propostas apresentadas pelas pesquisas realizadas nos últimos cinco anos sobre o uso das TDICs para a superação das dificuldades dos estudantes com TEA no seu processo de alfabetização e aprendizagem?

Para responder a essa pergunta, este artigo apresenta uma revisão sistemática da literatura acerca de pesquisas nacionais que discutem o uso das Tecnologias Digitais da Informação e Comunicação (TDICs) no processo de alfabetização e aprendizagem de pessoas com Transtorno do Espectro do Autismo (TEA).

\section{Procedimentos metodológicos}

Foi realizada uma busca avançada (advanced search) dos artigos indexados nas bases eletrônicas de dados, Scielo e Capes, utilizando os descritores: Transtorno do Espectro do Autismo, Autismo, Tecnologia, Alfabetização, Educação, Aprendizagem e Software, combinados entre si. Para a seleção dos estudos, estabeleceu-se como critério de inclusão: a) pesquisas nacionais que investigam o uso das TDICs para alfabetização e aprendizagem de pessoas com TEA publicadas entre 2014 e 2019.

De igual modo, foram estabelecidos os seguintes critérios de exclusão: a) artigos cujos estudos estivessem voltados à esfera da saúde; b) estudos nos quais as TDICs foram utilizadas com sujeitos sem TEA; c) artigos repetidos em ambas as bases de dados.

Inicialmente, foram encontrados 198 artigos e, em seguida, aplicados os critérios de exclusão e inclusão dos estudos. Para tanto, foi realizada a revisão dos títulos e resumos, assim como a leitura integral dos textos. Após essa etapa foram selecionados sete artigos que compõem o corpus desta pesquisa (Figura 2). 


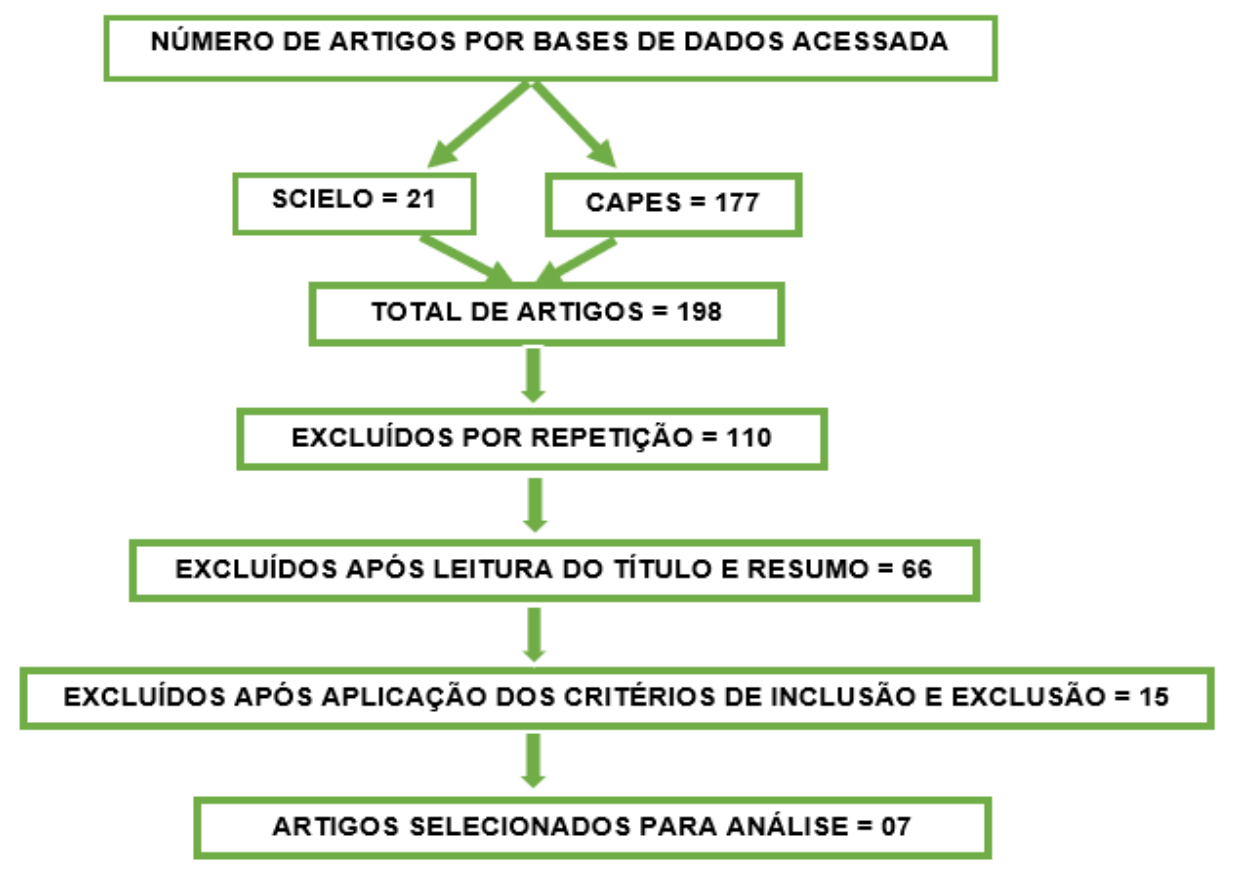

Figura 2: Esquema das etapas de seleção dos artigos. Fonte: Elaborado pelas autoras.

Como estratégia de análise, os artigos foram categorizados de acordo com a quantidade de pesquisas por ano de publicação (Gráfico 1), objetivos (Gráfico 2), área de pesquisa/formação dos autores, recurso tecnológico utilizado e tipo da pesquisa (Quadro 1).

Desse modo, os artigos analisados neste estudo foram dispostos em dois grupos de acordo com os objetivos propostos. Assim, o Grupo 1, 71\%, é composto pelas pesquisas que analisam o uso de recursos digitais já disponíveis no mercado e que podem ser utilizados por pessoas com ou sem deficiência e/ou transtornos. No Grupo 2, $29 \%$, foram reunidos os estudos que avaliam e discutem os resultados de recursos desenvolvidos pelas equipes pesquisadoras com o intuito de contribuir com o processo de alfabetização e aprendizagem de pessoas com TEA. 
Gráfico 1: distribuição dos artigos por ano de publicação (2014-2019).

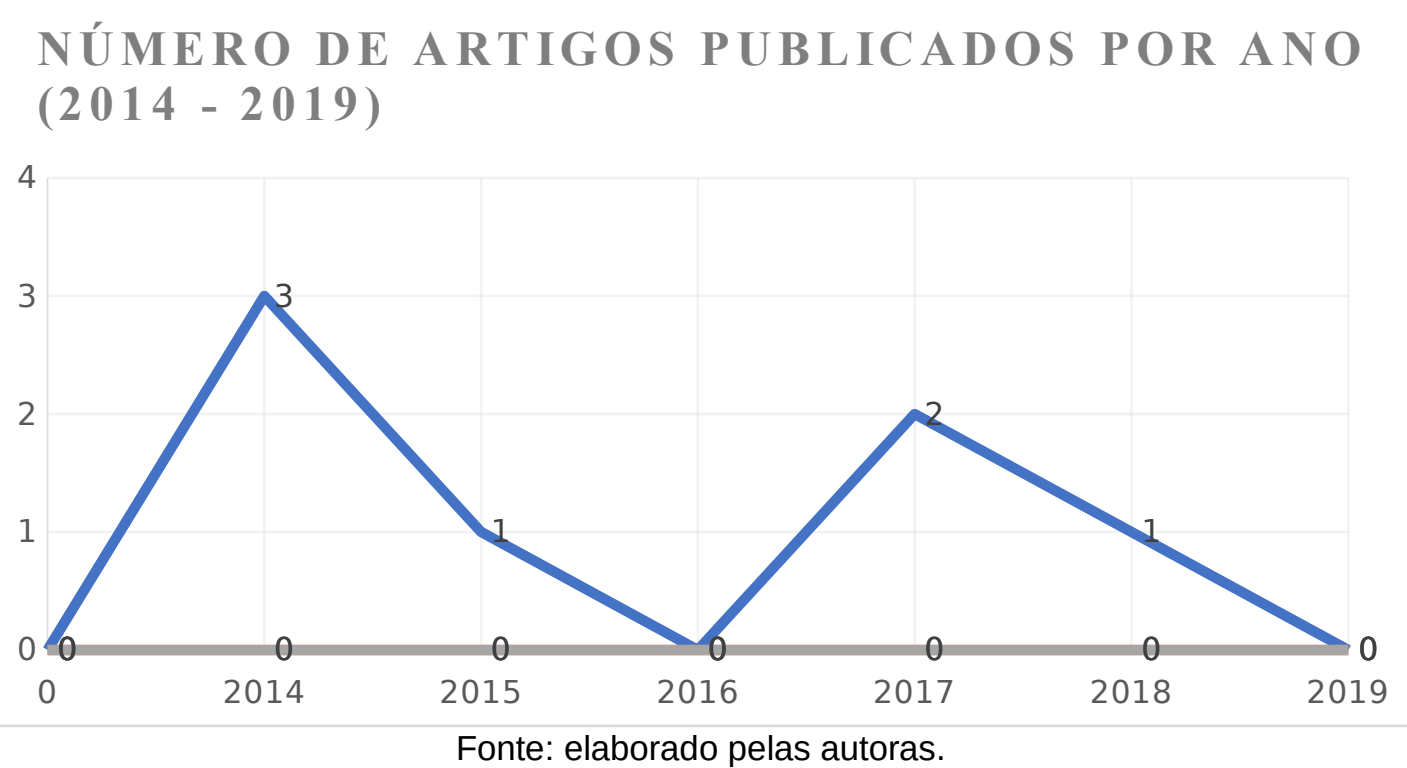

Gráfico 2: agrupamento das pesquisas de acordo com os objetivos propostos.

PERCENTUAL DE ARTIGOS DE ACORDO COM OS OBJETIVOS PROPOSTOS

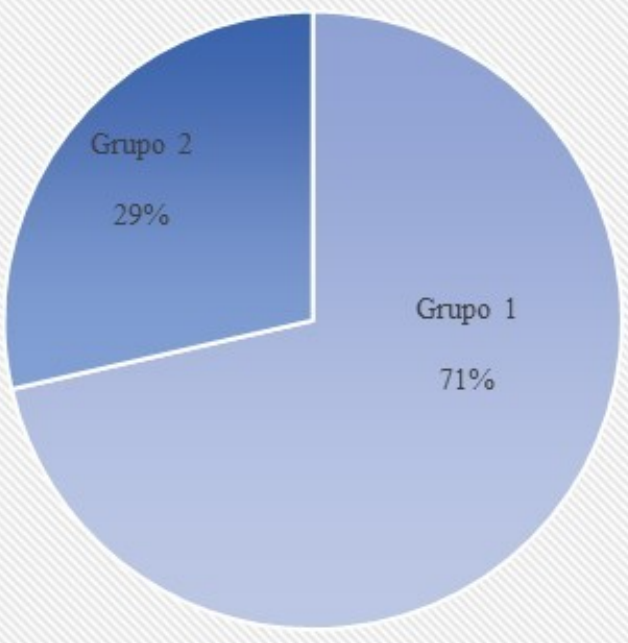

Fonte: elaborado pelas autoras. 
Quadro 1: categorização dos artigos publicados acerca do tema - Recursos tecnológicos aplicados à alfabetização e aprendizagem da pessoa com TEA (2014-2019).

\begin{tabular}{|c|c|c|c|c|c|c|}
\hline Título/Autores & $\begin{array}{l}\text { Descrição do } \\
\text { estudo }\end{array}$ & $\begin{array}{c}\text { Área de } \\
\text { pesquisa do(a)s } \\
\text { autores (as) }\end{array}$ & $\begin{array}{c}\text { Recurso } \\
\text { tecnológico } \\
\text { utilizado }\end{array}$ & Tipo & $\begin{array}{l}\text { Agrupamento } \\
\text { das pesquisas } \\
\text { de acordo com } \\
\text { os objetivos }\end{array}$ & Periódico/Ano \\
\hline $\begin{array}{l}\text { 1. A Comunicação } \\
\text { Alternativarara } \\
\text { além } \\
\text { Tecnologias das } \\
\text { Assistivas. } \\
\text { (NUNES; } \\
\text { WALTER, 2014) }\end{array}$ & $\begin{array}{l}\text { Apresenta e } \\
\text { comenta recursos } \\
\text { de Comunicação } \\
\text { Alternativa } \\
\text { elaborados com o } \\
\text { propósito de } \\
\text { favorecer as } \\
\text { habilidades } \\
\text { linguísticas, } \\
\text { comunicativas e } \\
\text { sociais de alunos } \\
\text { com autismo em } \\
\text { suas interações } \\
\text { em sala de aula. }\end{array}$ & $\begin{array}{l}\text { Psicologia } \\
\text { Fonoaudiologia }\end{array}$ & $\begin{array}{c}\text { Pranchas e } \\
\text { programas de } \\
\text { Comunicação } \\
\text { Alternativa-CA } \\
\text { Computadores, } \\
\text { Impressoras, } \\
\text { Máquina de } \\
\text { plastificação }\end{array}$ & Qualitativa & Grupo 1 & $\begin{array}{l}\text { Dossiê Educação } \\
\text { Especial: } \\
\text { diferenças, } \\
\text { currículo } \\
\text { processos de } \\
\text { ensino } \\
\text { aprendizagem } / 20 \\
14 .\end{array}$ \\
\hline $\begin{array}{l}\text { 2. As tecnologias } \\
\text { touch: corpo, } \\
\text { cognição } \\
\text { subjetividade. } \\
\text { (PELLANDA; } \\
\text { DEMOLY, 2014) }\end{array}$ & $\begin{array}{l}\text { Prepara um } \\
\text { quadro teórico } \\
\text { para suportar uma } \\
\text { pesquisa empírica } \\
\text { que usa as } \\
\text { tecnologias touch } \\
\text { com o objetivo de } \\
\text { mobilizar } \\
\text { cognitiva } \\
\text { afetivamente e } \\
\text { sujeitos } \\
\text { portadores de } \\
\text { patologias } \\
\text { cognitivas, } \\
\text { principalmente } \\
\text { autismo. } \\
\end{array}$ & Educação & iPAD & Empírica & Grupo 1 & $\begin{array}{l}\text { Psicologia Clínica/ } \\
2014 .\end{array}$ \\
\hline 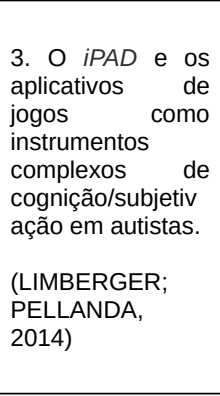 & 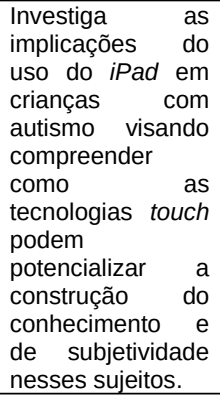 & $\begin{array}{l}\text { Psicologia } \\
\text { Educação }\end{array}$ & $\begin{array}{l}\text { Aplicativos de } \\
\text { jogos do } i P A D\end{array}$ & Qualitativa & Grupo 1 & $\begin{array}{l}\text { Revista Jovens } \\
\text { Pesquisadores/20 } \\
14 \text {. }\end{array}$ \\
\hline $\begin{array}{l}\text { 4. Tecnologias } \\
\text { Móveis r na } \\
\text { Inclusão Escolar e } \\
\text { Digital r de } \\
\text { Estudantes com } \\
\text { Transtornos de } \\
\text { Espectro Autista. } \\
\\
\text { (SANTAROSA; } \\
\text { CONFORTO, D, } \\
\text { 2015) }\end{array}$ & $\begin{array}{l}\text { Discute os limites } \\
\text { e as } \\
\text { possibilidades do } \\
\text { uso de recursos } \\
\text { tecnológicos } \\
\text { disponibilizados } \\
\text { por programas de } \\
\text { inclusão escolar e } \\
\text { digital na rede } \\
\text { pública brasileira } \\
\text { de ensino, quanto } \\
\text { à funcionalidade } \\
\text { com estudantes } \\
\text { com autismo. }\end{array}$ & Educação & $\begin{array}{l}\text { Laptop } \\
\text { iPAD }\end{array}$ & $\begin{array}{l}\text { Qualitativa } \\
\text { Exploratória } \\
\text { e explicativa }\end{array}$ & Grupo 1 & $\begin{array}{l}\text { Revista } \\
\text { derasileira } \\
\text { Especial/2015. }\end{array}$ \\
\hline $\begin{array}{l}5 . \text { A tecnologia } \\
\text { assistiva } \text { Scala } \\
\text { como recurso } \\
\text { para produção de } \\
\text { narrativas } \quad \text { e } \\
\text { registro de dados } \\
\text { nas pesquisas em }\end{array}$ & $\begin{array}{lr}\text { Apresenta } & 0 \\
\text { Sistema } & \text { de } \\
\text { Comunicação } & \\
\text { Alternativa } & \text { para } \\
\text { Letramento } & \text { de } \\
\text { Pessoas } & \text { com } \\
\text { Autismo (SCALA) }\end{array}$ & Educação & Aplicativo SCALA & Qualitativa & Grupo 2 & $\begin{array}{l}\text { RIAEE Revista } \\
\text { Ibero-Americana } \\
\text { de Estudos em } \\
\text { Educação/2017. }\end{array}$ \\
\hline
\end{tabular}




\begin{tabular}{|c|c|c|c|c|c|c|}
\hline $\begin{array}{l}\text { educação: uma } \\
\text { experiência com } \\
\text { pessoas adultas } \\
\text { com transtorno do } \\
\text { espectro autista. } \\
\text { (BITTENCOURT; } \\
\text { FUMES, 2017) }\end{array}$ & $\begin{array}{l}\text { para produção de } \\
\text { textos narrativos } \\
\text { por adultos com } \\
\text { autismo. }\end{array}$ & & & & & \\
\hline $\begin{array}{l}\text { 6. Uso de objeto } \\
\text { educacional } \\
\text { digital na } \\
\text { perspectiva da } \\
\text { educação } \\
\text { especial: Relato } \\
\text { de uma prática } \\
\text { pedagógica. } \\
\text { GONÇALVES; } \\
\text { PICHARILLO; } \\
\text { PEDRINO, 2017) }\end{array}$ & $\begin{array}{l}\text { Descreve uma } \\
\text { experiência de } \\
\text { utilização de um } \\
\text { software } \\
\text { educativo para } \\
\text { todos os alunos e, } \\
\text { especialmente, } \\
\text { para aluno com } \\
\text { Transtorno do } \\
\text { Espectro Autista } \\
\text { matriculado em } \\
\text { sala comum da } \\
\text { educação infantil. }\end{array}$ & Educação & Software JClic & $\begin{array}{l}\text { Experimental } \\
\text { Estudo de caso }\end{array}$ & Grupo 1 & $\begin{array}{l}\text { Revista online de } \\
\text { Política e Gestão } \\
\text { Educacional/2017 } \\
\text {. }\end{array}$ \\
\hline  & 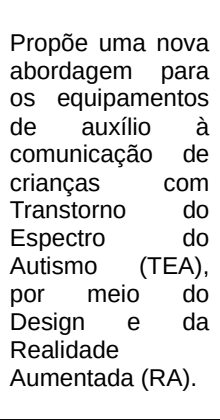 & Design & $\begin{array}{c}\text { Smartphone } \\
\text { Realidade } \\
\text { Aumentada } \\
\text { (Aurasma) } \\
\text { Prancha de } \\
\text { comunicação } \\
\text { alternativa }\end{array}$ & $\begin{array}{c}\text { Exploratória } \\
\text { Estudo de caso }\end{array}$ & Grupo 2 & $\begin{array}{l}\text { Design \& } \\
\text { Tecnologia/2018. }\end{array}$ \\
\hline
\end{tabular}

Fonte: Quadro elaborado pelas autoras.

\section{Revisão da literatura}

A dinâmica relação do homem com o mundo tem impulsionado a criação de novos instrumentos que representam uma verdadeira revolução no modo de vida e, em alguns casos, uma relação de quase dependência do homem pela tecnologia, como se ela fosse uma extensão de seu próprio corpo (MCLUHAN, 1969).

As TDICs têm causado diversas mudanças nas sociedades contemporâneas, como, por exemplo, nos modos de interação entre seus usuários e os processos de ensino e aprendizagem apresentados ou viabilizados por esses instrumentos.

Destarte, pode-se observar que as TDICs atendem públicos que variam entre os que possuem o domínio acerca do letramento digital e foram denominados pelo norteamericano Marc Prensky em outubro de 2001 como "nativos digitais" (RIBEIRO, 2018, p. 44; MATTAR, 2010, p. 10), até aqueles que não detêm sequer o domínio da escrita, tampouco alto grau de intimidade com a tecnologia. Assim, é possível afirmar que ela possibilita a inclusão digital de indivíduos dos mais diversos níveis de conhecimento, bem como das mais distintas classes sociais.

Nessa direção, as pessoas com deficiência e/ou transtorno também necessitam ser cada vez mais incluídas nesse grupo, uma vez que é possível que sejam beneficiadas com a chegada das TDICs no ambiente escolar. Outrossim, é possível afirmar que esses recursos surgem como possibilidades de auxílio nos processos de aprendizagem de pessoas com deficiências, bem como daquelas com TEA, em virtude de funcionarem como instrumentos mediadores na interação desses sujeitos. 
Reconhecendo tal importância, este estudo objetiva realizar uma revisão sistemática da literatura acerca das pesquisas nacionais que discutem o uso das Tecnologias Digitais da Informação e Comunicação (TDICs) no processo de alfabetização e aprendizagem de pessoas com Transtorno do Espectro do Autismo (TEA).

Com essa revisão sistemática da literatura, constatou-se que, concernente ao número de publicações realizadas no espaço temporal demarcado (2014-2019), pode ser considerado que houve pouca ocorrência de pesquisas que abordam a temática em análise. A revisão dos estudos realizados nesse período permitiu que fosse observado que 2014 foi o ano com mais trabalhos publicados, três artigos. Em 2015, apenas um, em 2017, dois e, em 2018, um artigo publicado. Nos anos de 2016 e 2019 não foram encontrados artigos a respeito da temática. Em se tratando do ano de 2019, essa ausência pode ser justificada pelo fato de o levantamento dos dados ter sido concluído no primeiro quadrimestre do ano.

Entretanto, levando em conta que o número de pessoas diagnosticadas com TEA vem aumentando significantemente no Brasil e no mundo, assim como a existência, no Brasil, de políticas públicas voltadas à inclusão escolar das pessoas com deficiências e transtornos (BRASIL, 1988; 2008, 2012, 2015), esses dados foram considerados relevantes, pois, embora as TDICs estejam tão presentes na vida das pessoas, percebese que poucos trabalhos estão sendo publicados a respeito do uso desses recursos, bem como poucos incentivos para a divulgação de estudos a respeito desse assunto.

No que se refere às áreas de estudos às quais se dedicam os autores ou sua área de formação, verificou-se que a Educação demonstrou maior interesse em pesquisar sobre a temática analisada, embora houvesse algum interesse por parte da Psicologia, Fonoaudiologia e do Design, e isso não pode ser desconsiderado.

Esse dado leva a acreditar que essa deve ser a área que está sendo mais afetada pela falta de conhecimentos sobre o assunto, uma vez que os sistemas de ensino inclusivos recebem estudantes com TEA e, caso não disponham de condições materiais e humanas adequadas, não podem ofertar uma educação de qualidade para eles.

Já em relação aos recursos tecnológicos utilizados, foi observado que houve uma diversidade nesse quesito. Três estudos (PELLANDA; DEMOLY, 2014; LIMBERGER; PELLANDA, 2014; SANTAROSA; CONFORTO, 2015) se valeram do iPad na busca de soluções para a aprendizagem das pessoas com TEA. As demais pesquisas (NUNES, WALTER, 2014; BITTENCOURT; FUMES, 2017; GONÇALVES. PICHARILLO; PEDRINO, 2017; ROSA; SILVA; AYMONE, 2018) recorreram ao uso de outros meios, como laptops, tablets, smartphones, desktop, bem como a alguns softwares já existentes no mercado, assim como outros criados pelas equipes e testados por elas.

Em se tratando do tipo dos estudos, observou-se que a maioria dos pesquisadores elegeu a abordagem qualitativa, que, conforme Brasileiro (2013), se ocupa da interpretação dos fenômenos e da atribuição de significados no decorrer da pesquisa. No entanto, houve diversidade quanto aos métodos utilizados. Esses variaram entre estudos de caso, método exploratório e explicativo.

Partindo para a discussão sobre os grupos de análise categorizados nesta revisão (Gráfico 2), percebe-se que houve maior prevalência de pesquisas que analisam o uso de recursos digitais já disponíveis no mercado e que podem ser utilizados por pessoas com ou sem deficiência e/ou transtornos (NUNES; WALTER, 2014; PELLANDA; DEMOLY, 
2014; LIMBERGER; PELLANDA, 2014; SANTAROSA; CONFORTO, 2015; GONÇALVES; PICHARILLO; PEDRINO, 2017) - Grupo 1. Para esse agrupamento foram encontrados cinco artigos, o que equivale a $71 \%$ dos trabalhos investigados.

Em um deles, (NUNES; WALTER, 2014), foram apresentados três projetos de formação de recursos humanos para introduzir a comunicação alternativa nas escolas. Esses projetos consistiram em intervenções com estudantes de Pedagogia, estagiáriosmediadores, professores regulares e professores do Atendimento Educacional Especializado (AEE), de modo a prepará-los para trabalhar, utilizando materiais construídos com a ajuda das tecnologias, com crianças que possuem dificuldades na comunicação oral, dentre eles, estudantes com TEA.

$\mathrm{Na}$ verdade, esse estudo demonstrou que as TDICs foram utilizadas como um recurso auxiliar para a confecção do material utilizado na intervenção com os alunos que possuíam dificuldades na comunicação oral. Seu uso ocorreu de forma a possibilitar que os profissionais pudessem realizar pesquisas e impressão de figuras para confecção de pranchas de comunicação alternativa. Esse é outro dado que revela uma problemática relativa à falta de recursos para o trabalho com esses estudantes.

De acordo com esses pesquisadores, o uso dos recursos de comunicação alternativa no contexto regular de ensino possibilitou, em diversas situações e contextos, condições de comunicação/interação mais eficazes e de maior clareza na compreensão dos alunos.

Essa pesquisa constatou que profissionais na área de educação se sentem despreparados para trabalhar com as crianças com TEA, o que revela uma lacuna na formação inicial e continuada desses sujeitos que estão diretamente envolvidos na aprendizagem dos estudantes com deficiência e/ou transtornos e, por isso, têm uma grande importância nesse processo.

Nesse sentido, foi observado ainda que, embora as TDICs não tenham sido utilizadas diretamente pelo estudante, elas estiveram presentes no processo de construção dos recursos que foram utilizados para favorecer a interação dessas pessoas. Isso possibilita a reflexão de que as TDICs, mesmo que indiretamente, desempenham um papel de suma importância para a mediação na aprendizagem, de modo a possibilitar 0 desenvolvimento da competência comunicativa dos estudantes com TEA.

Embora os resultados da intervenção tenham sido positivos, eles revelam que o processo de aquisição da competência comunicativa ultrapassa a inserção de linguagens alternativas na rotina das pessoas, uma vez que esse processo implica uma mudança de atitude dos interlocutores frente à diversidade de possibilidades para tornar a comunicação significativa e efetiva.

Ainda nesse grupo, três estudos (PELLANDA; DEMOLY, 2014; LIMBERGER; PELLANDA, 2014, SANTAROSA; CONFORTO, 2015) utilizaram o iPad como recurso para intervenções na aprendizagem das crianças autistas. Dois deles, (PELLANDA; DEMOLY, 2014; LIMBERGER; PELLANDA, 2014), foram realizados pela mesma equipe de estudiosos. Um deles, (PELLANDA; DEMOLY, 2014), teve por preocupação utilizar ferramentas do iPad para investigar a relação dessas crianças com 0 artefato, percebendo que, por meio do contato com jogos que estimulam a linguagem, houve uma reconfiguração dos seus processos cognitivos, fazendo com que ocorressem avanços no modo de interação. Nas experiências relatadas durante os estudos, as pesquisadoras 
constataram que houve o deslocamento do foco de interesse das crianças, que antes era fixado em objetos, passando para as pessoas envolvidas nas atividades e para os jogos do iPad.

Outro dado importante nesse trabalho é que uma das crianças investigadas não interagia por meio da linguagem oral e, com as intervenções desses jogos, ela apresentou avanços, chegando, inclusive, a interagir oralmente em algumas atividades em sala de aula. Desse modo, os resultados foram positivos, embora a pesquisa ainda estivesse em uma fase bastante inicial.

Além disso, as autoras verificaram também que houve um ganho para as crianças no que concerne à construção ou aperfeiçoamento de sua autoria e superação da limitação referente ao processo de escolha, pois uma delas demonstrou essa atitude para escolher os jogos que mais lhe agradavam, bem como formas de "linguajar" elegidas por ela (PELLANDA; DEMOLY, 2014).

Outra constatação que chamou a atenção nesse trabalho foi o fato de que as crianças interagiram melhor com a tecnologia touch, haja vista que, conforme as pesquisadoras, o contato da ponta dos dedos diretamente na tela pode ativar regiões do cérebro até então menos ativas, o que demonstra a importância do uso da tecnologia como auxílio para a potencialização dos processos cognitivos das crianças com TEA, cujas interações por meio da linguagem ainda hoje configuram-se como grandes desafios para diversos profissionais e familiares.

Além disso, as autoras do artigo em questão, se propuseram a construir um quadro teórico para embasar suas hipóteses em relação às potencialidades do instrumento utilizado para o desenvolvimento da interação das crianças observadas.

A segunda pesquisa (LIMBERGER; PELLANDA, 2014) também utilizou os jogos que estão disponíveis no iPad para investigar como as tecnologias touch podem potencializar a construção do conhecimento e a subjetividade dos autistas. Nesse caso, os autores do estudo defendem que o jogo age como um simulador de realidade, em que há uma diminuição da ansiedade, permitindo à criança entender melhor como funcionam as relações com o outro e começar a obter mais sucesso e segurança quando essas relações se tornam concretas.

Isso implica dizer que o jogo no ambiente digital pode ser um grande aliado para melhorar as relações da criança com TEA junto a outras pessoas, tendo em vista que ele promove a regulação das emoções à medida que simula situações da realidade, possibilitando a vivência dessas experiências por meio do virtual e, posteriormente, permitir que o autista possa lidar com essas emoções em contextos reais. Normalmente, se não houver qualquer intervenção, essa situação representa algo difícil de ser superado devido à dificuldade no processo de interação social causado pelo transtorno.

Esses trabalhos apontam que o uso da tecnologia auxilia na superação de dificuldades das crianças com TEA em relação à aquisição da linguagem, bem como na melhoria das relações sociais. Assim, foi constatado que essas duas características, que são tão marcantes na diagnose do TEA e que tanto dificultam a relação daqueles que convivem com esses sujeitos, podem ser superadas.

No terceiro trabalho desse grupo, (SANTAROSA; CONFORTO, 2015), foram analisados os limites e possibilidades da configuração tecnológica utilizada para apoiar estudantes com TEA em sala de aula. As autoras acompanharam três estudantes em 
processo de alfabetização e observaram uma falha referente ao design de laptops ofertados por um programa de inclusão digital em escolas públicas.

Foi observado também que as crianças, ao manusearem os laptops ofertados pelo programa de inclusão digital, apresentaram muita dificuldade e resistência, principalmente quanto ao formato da tela, que tinha uma configuração muito pequena, além de os outros componentes da máquina, como o mouse e o teclado, não proporcionarem uma maior acessibilidade aos estudantes.

Quando houve a possibilidade de utilização do iPad, por uma das crianças, houve uma maior interação/aceitação do equipamento. Nesse caso, o recurso não fazia parte do programa de inclusão digital ofertado pelo governo, porém foi inserido na pesquisa, pois essa criança já o possuía e as estudiosas decidiram fazer uma comparação dos resultados obtidos em relação aos demais que continuaram utilizando os laptops ofertados pelo programa do governo.

Foi percebido, então, que o processo de aprendizagem transcorreu melhor devido à facilidade no manuseio do equipamento e pelo modo como o estudante interagia com os jogos e demais aplicativos contidos nele. Outro fator que favoreceu a pesquisa foi a praticidade de locomoção do aparelho.

Nesse caso, as pesquisadoras ressaltam a necessidade de observarem-se as características dos sujeitos aos quais a tecnologia será destinada, visto que cada indivíduo possui suas peculiaridades e, principalmente indivíduos com TEA, que apresentam tantas singularidades em seu desenvolvimento. Dessa forma, tais singularidades precisam ser consideradas, inclusive no momento de desenvolvimento de sistemas e/ou aparelhos que serão usados por eles.

As reflexões levantadas pelas autoras do estudo em questão demonstram que, muitas vezes, há uma homogeneidade na utilização de dispositivos tecnológicos com as pessoas com deficiência e/ou transtornos, sem considerar suas especificidades. Em alguns casos, não se faz um estudo prévio para identificar quais recursos seriam mais adequados às peculiaridades de cada indivíduo.

Nessa mesma direção, dentre os estudos que fazem parte desse grupo, uma pesquisa realizada com estudantes da educação infantil, (GONÇALVES. PICHARILLO; PEDRINO, 2017), utilizou um software educativo (JClic), que visava ao desenvolvimento da atenção dos escolares para uma escuta atenta dos recursos sonoros utilizados no referido software.

A partir de uma atividade envolvendo todos os alunos da sala, incluindo uma criança diagnosticada com TEA e outra com déficit na linguagem oral, as pesquisadoras perceberam que houve bastante cooperação, atenção e a participação das crianças, principalmente daquelas que possuíam dificuldades em iniciar a interação, bem como estabelecer a oralização frente à fala do outro. Desse modo, a ferramenta facilitou a potencialização de sua aprendizagem.

A atividade consistia em escolher um animal no notebook e imitar o som produzido pelo respectivo animal. Isso demandava a mobilização de habilidades como: atenção, concentração e escuta atenta, habilidades essas que, para uma pessoa com TEA, representa um grande esforço.

As estudiosas perceberam que o uso da tecnologia favoreceu o desenvolvimento das habilidades comunicativas das crianças que apresentavam déficit nessa área. No 
decorrer da atividade, o estudante com TEA passou a arriscar produção de frases inteiras e a interagir com mais colegas, tanto em sala como em outros ambientes da escola. Já aquele que possuía dificuldade em se expressar oralmente passou a pronunciar palavras curtas e ampliou sua interação com outras pessoas.

Nessa pesquisa, as autoras também destacam a importância do planejamento das atividades, no sentido de buscar o recurso tecnológico adequado à faixa etária e às peculiaridades do público-alvo, levando em consideração os objetivos que se deseja alcançar, mas também considerando possíveis dificuldades e habilidades dos sujeitos. Ou seja, o professor precisa ter clareza do que pretende que seus alunos desenvolvam/aprendam e o modo como avaliará se isso foi contemplado (GONÇALVES; PICHARILLO; PEDRINO, 2017). Portanto, a mediação consciente do professor é de suma importância para o desenvolvimento de estratégias que possibilitem a aprendizagem por meio da tecnologia.

Passando para a análise do Grupo 2, observando os artigos cujo objetivo fora avaliar e discutir os resultados de recursos desenvolvidos pela equipe pesquisadora para o processo de alfabetização e aprendizagem de pessoas com TEA, foram encontrados apenas dois estudos, (BITTENCOURT; FUMES, 2017; ROSA; SILVA; AYMONE, 2018), o que representa $29 \%$ dos trabalhos investigados.

Um desses estudos, (BITTENCOURT; FUMES, 2017), que, tomando por base o entendimento de que pessoas com TEA são capazes de pensar sobre situações dentro e fora da escola, demonstrando uma autoconsciência que historicamente não é associada a eles, utilizou o módulo de narrativas visuais para construção de histórias do aplicativo SCALA para que adultos autistas, entre 30 e 36 anos, criassem narrativas visuais e, em seguida, narrativas orais acerca de fatos do cotidiano.

No aplicativo desenvolvido pela equipe da pesquisa e disponibilizado gratuitamente, são apresentadas as possibilidades de o usuário criar narrativas a partir de imagens disponibilizadas pelo programa ou produzidas pelo próprio sujeito, por meio de recursos contidos nas ferramentas do aplicativo digital.

A partir de um tema ofertado, "A escola", quatro adultos escolarizados (três do sexo masculino e um do sexo feminino) representaram suas vivências no contexto escolar, por meio das imagens disponibilizadas no aplicativo. Essa atividade possibilitou a esses sujeitos vivenciarem situações comunicativas nas quais puderam narrar, pelas imagens, detalhes de seu cotidiano. Essas imagens não haviam sido capturadas anteriormente a partir de entrevistas.

Vale salientar que esse foi o único artigo que teve como público-alvo pessoas adultas com TEA. Essa informação demonstrou que a maioria das pesquisas a respeito desses sujeitos são direcionadas ao público infantil. Esse fato evidencia a necessidade de ampliação desses estudos incluindo neles as dificuldades enfrentadas por pessoas na fase adulta.

Outra pesquisa desse grupo, (ROSA; SILVA; AYMONE, 2018), teve como objetivo propor um novo design para a criação de uma prancha de comunicação aumentativa e alternativa (CAA) para crianças com TEA. Os pesquisadores projetaram e produziram um protótipo de uma prancha com o recurso da Realidade Aumentada (RA), utilizando objetos reais em formato tridimensional. Para tanto, houve uma análise inicial dos tipos de prancha existentes, observando-se os símbolos utilizados, suas limitações e 
possibilidades de facilitar o uso pela criança. Após esse momento, os autores utilizaramse do software Autodesk 3DS Max para a elaboração do design dos símbolos e de um aplicativo chamado Aurasma. Esse aplicativo teve como intuito a criação de animações, possibilitando que as imagens adquirissem movimentos.

Nesse estudo foram selecionadas seis crianças do sexo masculino: uns considerados verbais e outros não-verbais. Os pesquisadores desenvolveram nove pictogramas para uma prancha de comunicação e o aplicativo foi instalado em smartphones. À medida que se apontava o aparelho móvel para uma imagem da prancha, essa imagem ganhava movimentos. Esse fato despertava o interesse das crianças com TEA, o que possibilitou uma maior interação desses indivíduos por meio da linguagem oral, pois as crianças imitavam sons produzidos por algumas imagens ou se expressavam por meio de palavras, além de imitarem alguns movimentos dos pictogramas.

Deve-se destacar que, entre todos os artigos analisados, esse foi o único em que os pesquisadores levaram em consideração a participação dos pais para o uso do aplicativo em outros ambientes com seus filhos. Para tanto, foi elaborado um manual de instruções a fim de orientar como o aplicativo poderia ser instalado e utilizado pelos usuários.

Embora os estudiosos tenham observado avanços significativos quanto à interação das crianças após o uso do aplicativo, foram percebidas algumas falhas que necessitaram de alguns ajustes, tais como: o tempo de espera que os recursos de animação levavam para funcionar devido à lentidão da internet, assim como, em alguns momentos, as animações não funcionavam por falha do aplicativo.

Essas questões devem ser observadas, pois, dependendo do nível do sujeito com TEA, a quebra na expectativa pode causar uma desestabilização no comportamento da criança, e isso pode comprometer a eficácia do trabalho.

Devido à carência de trabalhos que tenham como foco o uso das Tecnologias Digitais da Informação e Comunicação (TDICs) no ambiente educacional para auxiliar no processo de alfabetização e aprendizagem de pessoas com autismo, constata-se que existe uma grande necessidade de ampliação desses estudos, fato também observado por vários autores consultados neste trabalho.

\section{Considerações finais}

Este trabalho teve como objetivo apresentar uma revisão sistemática da literatura acerca de pesquisas nacionais que discutem o uso das Tecnologias Digitais da Informação e Comunicação (TDICs) no processo de alfabetização e aprendizagem de pessoas com Transtorno do Espectro do Autismo (TEA).

Com a realização da pesquisa, percebeu-se que os artigos selecionados se ocuparam de investigar o uso das TDICs pelas pessoas (crianças e adultos) com TEA em seu processo de aprendizagem, comunicação, letramento e alfabetização. Desse modo, se subdividiram em áreas distintas do conhecimento, tais como: Saúde (Psicologia e Fonoaudiologia), Educação e Design. Para tanto, cada estudo foi realizado em locus diversos, bem como a partir de diferentes metodologias e objetivos para obtenção dos resultados. 
Diante da análise dos artigos, foi observada a importância e a necessidade de um novo olhar a respeito do uso das TDICs no ambiente educacional para propiciar a aprendizagem de pessoas com TEA, visto que foi comprovada uma melhora considerável nos resultados dos participantes que utilizaram tais recursos.

Além disso, os estudos demonstraram que as tecnologias podem exercer a função de instrumentos mediadores para a aprendizagem, não só de crianças, como de jovens e adultos com o transtorno do espectro do autismo. Independente da faixa etária, as TDICs podem ter a mesma eficácia, desde que sejam realizadas as adequações necessárias às características de cada grupo.

Contudo, há que se considerar que algumas ferramentas também necessitam de avaliações prévias e durante o uso, para que as intervenções frente às dificuldades dos indivíduos com TEA surtam melhores efeitos.

Percebeu-se, ainda, que, no cenário nacional, há pouca ocorrência de estudos que tratem do tema abordado, demonstrando a necessidade de maiores investimentos no que concerne aos estudos na área, diante dos benefícios alcançados por eles.

Outro fator evidenciado após esta revisão de literatura é que os estudos, em sua maioria, utilizaram tecnologias já disponíveis no mercado para a intervenção frente às dificuldades apresentadas por sujeitos com TEA. A maioria desses recursos foram desenvolvidos para pessoas que não possuem deficiência, no entanto, puderam desempenhar um papel importante no processo de aprendizagem dos indivíduos que possuem o transtorno. Em contrapartida, poucas foram as pesquisas que discutiram o uso de TDICs elaboradas pelas equipes para contribuir com a superação de barreiras referentes à alfabetização e aprendizagem de pessoas com TEA.

Outra observação importante é que muitos trabalhos tiveram seu foco voltado para o uso da comunicação alternativa, com o intuito de intervir nas dificuldades de interação pela linguagem oral dos autistas. Isso pode ser justificado pelo fato de que essa é uma das principais características do transtorno.

Em suma, conclui-se que os artigos analisados apresentaram valiosas contribuições para que se possa repensar a alfabetização e a aprendizagem da pessoa com TEA, bem como o uso dos recursos tecnológicos enquanto instrumentos de mediação no processo de ensino e aprendizagem desses sujeitos, os quais ainda possuem pouca visibilidade diante de tantas dificuldades que vivenciam nas mais diversas esferas da sociedade.

\section{Referências}

AMERICAN PSYCHIATRIC ASSOCIATION (APA). Diagnostic and Statistical Manual of Mental Disorders, Fifth Edition (DSM-V). Arlington, VA: American Psychiatric Association, 2013.

BERSCH, R.; SCHIRMER, C. Tecnologia assistiva no processo educacional. Ensaios pedagógicos: construindo escolas inclusivas. Brasília: MEC/ SEESP, 2005. p. 87-92.

BITTENCOURT, I. G. S.; FUMES, N. L. F. A tecnologia assistiva Scala como recurso para 
produção de narrativas e registro de dados nas pesquisas em educação: uma experiência com pessoas adultas com transtorno do espectro autista. Revista Ibero-Americana de Estudos em Educação, Araraquara, SP, v. 12, n. esp. 2, p. 1481-1495, 2017.

BRAGA, W. C. Autismo azul e de todas as cores: guia básico para pais e profissionais. São Paulo: Paulinas, 2018.

BRASIL. Constituição Federal, de 5 de outubro de 1988. Brasília, DF, 1988. http://www.planalto.gov.br/ccivil_03/constituicao/constituicao.htm. Acesso em: 11 abr. 2019.

BRASIL. Lei 12.764, de dezembro de 2012. Institui a Política Nacional de Proteção dos Direitos da Pessoa com Transtorno do Espectro Autista; e altera o § 3odo art. 98 da Lei no 8.112, de 11 de dezembro de 1990. Brasília, DF, 2012. http://www.planalto.gov.br/ccivil_03/_ato2011-2014/2012/lei//12764.htm. Acesso em: 11 abr. 2019.

BRASIL. Política Nacional da Educação Especial na Perspectiva da Educação Inclusiva. Brasília, DF, 2008. http://portal.mec.gov.br/index.php? option=com docman\&view=download\&alias=16690-politica-nacional-de-educacaoespecial-na-perspectiva-da-educacao-inclusiva-05122014\&Itemid=30192. Acesso em: 15 de abr. 2019.

BRASIL. Lei 13.146, de 6 de julho de 2015. Institui a Lei Brasileira de Inclusão da Pessoa com Deficiência (Estatuto da Pessoa com Deficiência). Brasília, DF, 2015. http://www.planalto.gov.br/ccivil_03/_ato2015-2018/2015/lei/l13146.htm. Acesso em: 18 de abr. 2019.

BRASILEIRO, A. M. M. Manual de produção de textos acadêmicos e científicos. São Paulo: Atlas, 2013.

CANI, J. B.; COSCARELLI, C. V. Textos multimodais como objetos de ensino: reflexões em propostas didáticas. In: KERSH, D. F. COSCARELLI, C. V. CANI, J. B. (org.) Multiletramentos e multimodalidade: ações pedagógicas aplicadas à linguagem. São Paulo: Pontes, 2016. p. 15-47.

CASELLA, E. B.; CELERI, E. H. R. V.; MONTENEGRO, M. A. Transtorno do Espectro Autista - TEA: manual prático de diagnóstico e tratamento. Rio de Janeiro: Thieme Revinter; 2018.

COUTINHO, M. L. Psicogênese da língua escrita: o que é? Como intervir em cada uma das hipóteses? Uma conversa entre professores. In: MORAES A. G.; ALBUQUERQUE, E. B. C.; LEAL, T. F (org.). Alfabetização: apropriação do sistema de escrita alfabética. Belo Horizonte: Autêntica, 2005, p. 47-69.

FERREIRA, M. I. J Tecnologia assistiva para crianças com paralisia cerebral sem oralidade: avaliação da comunicação durante atividades com jogos digitais, 2011. 81 f. 
Dissertação. Faculdade de Tecnologia Senai/Cimatec, Salvador/BA, 2011.

FERREIRO, E.; TEBEROSKY, A. Psicogênese da língua escrita. Trad. Lichtenstein D.M, Di Marco L, Corso M. Porto Alegre: Artmed, 2007.

FIGUEIREDO, F. J. Q. Vygotsky: a interação no ensino/aprendizagem de línguas. São Paulo: Parábola, 2019.

FONSECA, M. E. G.; CIOLA, J. C. B. Vejo e aprendo: fundamentos do Programa TEACCH o ensino estruturado para pessoas com autismo. 2 ed. Ribeirão Preto, SP: Book Toy, 2016.

GONÇALVES, A. G.; PICHARILLO, A. D. M.; PEDRINO, M. C. O uso de objeto educacional digital na perspectiva da educação especial: relato de uma prática pedagógica. Revista On line de Política e Gestão Educacional. Araraquara, SP, v. 21, n. 3, p. 1726-1735, 2017.

HESS, E. B. DIR/Floortime: evidence based practice towards the treatment of autism and sensory processing disorder in children and adolescents. Int J Child Health Hum Dev. 6(3), p. 267-274, 2013.

KANNER, L. Autistic disturbances of affective contact. Nervous Child. 2(1), p. 217-50, 1943.

LAURENT, E. A batalha do autismo: da clínica à política. Rio de Janeiro: Zahar, 2014.

LEFRANÇOIS, G. R. Teorias da aprendizagem: o que o professor disse. Trad. Visconte S A. 6 ed. São Paulo: Cengage Learning, 2017.

LIMBERGER, L. S.; PELLANDA, N. M. C. O iPAD e os aplicativos de jogos como instrumentos complexos de cognição/subjetivação em autistas. Revista Jovens Pesquisadores. Santa Cruz do Sul, v. 4, n. 1, p. 149-58, 2014.

LOVAAS, O. I. Behavioral treatment and normal educational na intelectual functioning in Young autistic children. Journal Consult Clin Psyc. v. 55 n. 1, p. 3-9, 1987.

MATTAR, J. Games em educação: como os nativos digitais aprendem. São Paulo: Pearson Prentice Hall, 2010.

MCLUHAN, M. Os meios de comunicação como extensões do homem. São Paulo: Cultrix, 1969.

MORTATTI, M. R. L. Educação e letramento. São Paulo: UNESP, 2004.

NUNES, L. R. O. P.; WALTER, C. C. F. A Comunicação alternativa para além das tecnologias assistivas. Archivos Analíticos de Políticas Educativas. Arizona, v. 22, n. 83, p. 1-18, 2014. 
PALANGANA, I. C. Desenvolvimento e aprendizagem em Piaget e Vytotsky: a relevância do social. São Paulo: Summus Editorial, 1998.

PELLANDA, N. M. C. DEMOLY, K. R. A. As tecnologias TOUCH: corpo, cognição e subjetividade. Revista Psicologia Clínica. Rio de Janeiro, v. 26, n. 1, p. 69-89, 2014.

PISCHETOLA, M. Inclusão digital e educação: a nova cultura da sala de aula. Rio de Janeiro: Vozes; Editora PUC - Rio, 2016.

RIBEIRO, A. E. Escrever, hoje: palavra, imagem e tecnologias digitais na educação. São Paulo: Parábola, 2018.

ROSA, I. V.; SILVA, R. P.; AYMONE, J. L. F. Processo de desenvolvimento de Prancha de Comunicação Alternativa e Aumentativa para crianças com Transtorno do Espectro do Autismo utilizando Realidade Aumentada. Revista Design e Tecnologia. Rio Grande do Sul, v. 8, n. 15, p. 51-67, 2018.

SANTAROSA, L. M. C.; CONFORTO, D. Tecnologias móveis na inclusão escolar e digital de estudantes com Transtornos do Espectro Autista. Revista Brasileira de Educação Especial, Marília, SP, v. 21, n. 4, p. 349-366, 2015.

SOARES, M. Alfabetização: a questão dos métodos. São Paulo: Contexto, 2016.

VIGOTSKI, L. S. Pensamento e linguagem. 4. ed. São Paulo: Martins Fontes, 2008. Aprovado em dia 19 de dezembro de 2019. 